\begin{tabular}{|c|c|c|}
\hline $\begin{array}{l}\text { PKS } \\
\text { PUBLIC } \\
\text { KNOWLEDGE } \\
\text { PROSECT }\end{array}$ & $\begin{array}{c}\text { REVISTA DE GEOGRAFIA } \\
\text { (RECIFE) } \\
\text { http://www.revista.ufpe.br/revistageografia }\end{array}$ & 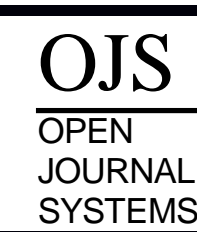 \\
\hline
\end{tabular}

\title{
ALTERAÇÕES MORFOLÓGICAS DE ENCOSTAS E DEFLAGRAÇÃO DE ESCORREGAMENTOS EM ÁREAS DENSAMENTE URBANIZADAS: UMA ANÁLISE EVOLUTIVA EM UMA SUB-BACIA DO MUNICÍPIO DE RECIFE (PE)
}

\author{
John Kennedy Ribeiro de Santana ${ }^{1}$, Fabrizio de Luiz Rosito Listo ${ }^{2}$
}

\begin{abstract}
${ }^{1}$ Mestrando do Programa de Pós-Graduação em Geografia da UFPE. E-mail: santanajohn87@gmail.com
${ }^{2}$ Docente do Departamento de Ciências Geográficas e do Programa de Pós-Gradução em Geografia da UFPE. E-mail: fabrizio.listo@ufpe.br
\end{abstract}

Artigo recebido em 14/03/2018 e aceito em 11/04/2018

\begin{abstract}
RESUMO
Na Região Metropolitana do Recife, é comum a ocorrência de escorregamentos, que causam diversos prejuízos econômicos e sociais. Nesse contexto, se destaca a sub-bacia do Córrego de Nova Descoberta (zona norte do Recife), que se caracteriza por apresentar encostas com declividades elevadas e intensa ocupação antrópica, onde são registrados anualmente muitos escorregamentos. Sendo as alterações antrópicas na morfologia das encostas importantes fatores condicionantes, o objetivo desta pesquisa é comparar a morfologia original e a morfologia antropogênica, avaliando a sua influência na potencialização dos escorregamentos. Para cumprir este objetivo, foi criado um mapa das ocorrências de escorregamentos a partir de banco de dados e trabalhos de campo. Para compreender a influência das alterações antrópicas sobre as encostas, foram elaborados perfis topográficos de anos distintos (1975 e 2013), criados em ambiente SIG (Sistema de Informações Geográficas). Os resultados mostraram que as encostas sofreram modificações consideráveis na sua morfologia original, o que potencializou a ocorrência de escorregamentos. Dessa forma, pode-se dizer que a ocupação criou knickpoints artificiais, ao longo do tempo, que romperam o perfil de equilíbrio das encostas e geraram taludes com declividades incompatíveis com os ângulos de repouso dos materiais que estruturam o relevo da região.
\end{abstract}

Palavras-chave: Escorregamentos; Perfis topográficos; Morfologia original e morfologia antropogênica; Sistemas de Informação Geográfica; Sub-bacia do Córrego de Nova Descoberta.

\section{SLOPES MORPHOLOGICAL CHANGES AND LANDSLIDES DEFLAGRATION IN DENSELY URBANIZED AREAS: AN EVOLUTIONARY ANALYSIS IN A WATERSHED OF RECIFE CITY (PE)}

\begin{abstract}
In the Metropolitan Region of Recife, it is common the landslides occurrence, which cause several economic and social damages. In this context, the Nova Descoberta basin (northern area of Recife) stands out, characterized by slopes with high slopes and intense anthropic occupation, where many landslides are recorded annually. As the anthropic changes in the morphology of the slopes are important conditioning factors, the objective of this research is to compare the original morphology and the anthropogenic morphology, evaluating its influence on the potential of the landslides. To achieve this goal, a map of landslides occurrence from database and field work was created. To understand the influence of anthropic changes on the slopes, topographic profiles of different years (1975 and 2013), created in a GIS (Geographic Information System) environment, were elaborated. The results showed that the slopes underwent considerable modifications in their original morphology, which increased the occurrence of landslides. In this way, it can be said that the occupation created artificial knickpoints, over time, that broke the slope equilibrium profile and generated slopes with slopes incompatible with the rest angles of the materials that structure the relief of the region.

Keywords: Landslides; Topographic profiles; Original morphology and anthropogenic morphology; Geographic Information System; Nova Descoberta basin.
\end{abstract}




\section{INTRODUÇÃO}

A organização desigual de muitas Regiões Metropolitanas no Brasil teve como uma de suas consequências, a ocupação de áreas consideradas de risco por populações de menor poder aquisitivo, tais como encostas muito declivosas e margens de rios; situação que vem contribuindo para o aumento de assentamentos precários em áreas impróprias para a moradia (FERNANDES et al., 2002; CARVALHO et al., 2007, entre outros). De acordo com os dados da CPRM (2016) (Serviço Geológico do Brasil), existem mais de três milhões de pessoas em áreas de risco no país, distribuídas em 773 mil moradias. Somente no estado de Pernambuco, há 48 mil moradias em locais de risco, onde vivem cerca de 193 mil pessoas (CPRM, 2016).

Embora os processos de inundação sejam os mais frequentes no Brasil, são os eventos de movimentos gravitacionais de massa (especialmente os escorregamentos), os que provocam o maior número de vítimas fatais. Em um levantamento feito pelo IPT (Instituto de Pesquisas Tecnológicas do Estado de São Paulo), entre 1998 e 2017, foram registrados aproximadamente 3.458 óbitos, causados por estes processos, destacando-se os eventos ocorridos na região da Serra do Mar (principalmente nos estados do Rio de Janeiro e de São Paulo), onde foram contabilizadas 969 vítimas fatais.

Apesar de serem fenômenos naturais, os escorregamentos são influenciados diretamente por ações antrópicas que modificam as condições naturais do relevo, por meio de cortes e de aterros para a construção de moradias, rodovias, ferrovias, aterros, lançamento concentrado de águas sobre as encostas, extração mineral, entre outros (DREW, 1983; SELBY, 1993; MONTGOMERY e DIETRICH, 1994; FERNANDES e AMARAL, 1996; GUERRA e MARÇAL, 2006; CARVALHO et al., 2007; RODRIGUES e LISTO, 2016). Assim, o crescente número de habitações em áreas naturalmente suscetíveis no Brasil, sem o adequado planejamento do uso da terra e sem a adoção de técnicas adequadas de estabilização, está aumentando a ocorrência de acidentes associados a estes processos, que muitas vezes acabam atingindo dimensões de desastres (TOMINAGA et al., 2007).

As intervenções humanas devem ser observadas como parâmetros importantes na deflagração dos escorregamentos, já que modificam e podem acelerar a dinâmica original do relevo, de rochas e de solos, regime hidrológico e o comportamento de processos morfodinâmicos em vários graus e, em consequência, a estabilidade da paisagem criando morfologias antropogênicas (RODRIGUES, 2005). Nesse sentido, ao longo do tempo, a morfologia original do relevo pode ser alterada, modificando as declividades originais, por exemplo, e aumento tanto a instabilidade quanto os graus de risco. 
No estado de Pernambuco, os municípios com maiores áreas de ocorrência e grau de suscetibilidade e de risco a escorregamentos localizam-se, predominantemente, na Região Metropolitana do Recife (RMR) e na Zona da Mata (CEPED, 2013). De acordo com o Atlas Brasileiro de Desastres Naturais (CEPED, 2013), dos 184 municípios do estado, 13 deles foram atingidos por estes processos, estando todos distribuídos, principalmente, nas mesorregiões localizadas na região leste do estado. Na Região Metropolitana do Recife, os escorregamentos são em geral do tipo translacional e se localizam, especialmente, sobre as áreas constituídas por sedimentos da Formação Barreiras (PFALTZGRAFF, 2007).

Considerando os aspectos geológicos e geomorfológicos, as encostas da Região Metropolitana do Recife apresentam uma grande instabilidade potencial, manifestada pela ocorrência de processos erosivos e por escorregamentos sobre as coberturas sedimentares miocênicas da Formação Barreiras, potencializadas pelas áreas antropizadas (ALHEIREOS, 1998; ARAI, 2006). Em toda a área Metropolitana do Recife, os fatores decorrentes da forma inadequada de ocupação das encostas são importantes condicionantes na deflagração dos escorregamentos, sendo agravados pelos condicionantes naturais (ex. litologia, declividade, forma da encosta, pluviometria, entre outros). Dessa forma, cortes nas encostas para a construção de moradias, aterros com solo remanescente dos cortes, acumulo de lixo, desmatamentos, inexistência de rede de drenagem, entre outras práticas inadequadadas, são fatores que influenciam na deflagração de tais processos (LIMA, 2002; PFALTZGRAFF, 2007).

No município de Recife, destaca-se, quanto à ocorrência de escorregamentos, o bairro de Nova Descoberta (zona norte da cidade), que se caracteriza por apresentar encostas com declividades elevadas e intensa ocupação antrópica. Nesse contexto, a Defesa Civil do Recife vem, anualmente, registrando vários eventos de escorregamentos na região, onde são realizados monitoramentos e ações mitigatórias nas áreas densamente ocupadas, especialmente na sub-bacia do Córrego de Nova Descoberta, inserida no bairro. Assim, ano a ano, a ocorrência de escorregamentos causa consequências econômicas negativas e significativas para a população local e, muitas vezes, vítimas fatais. Dessa forma, o objetivo deste trabalho é comparar a morfologia original das encostas na sub-bacia do Córrego de Nova Descoberta e a morfologia antropogênica, a partir das alterações antrópicas ao longo de um período evolutivo, avaliando a sua influência na potencialização dos escorregamentos na região. 


\section{ÁREA DE ESTUDO}

O bairro de Nova Descoberta perfaz uma área total de $1,8 \mathrm{~km}^{2}$ com uma população de 34.212 habitantes e densidade demográfica de 192,29 hab./ha (PREFEITURA DO RECIFE, 2010), ou seja, trata-se de uma região altamente urbanizada e adensada. Localiza-se na zona norte de Recife sendo um dos bairros com maior índice de exclusão social do município (FUNDAJ, 2007).

Inserida neste bairro, foi adotado como recorte escalar neste trabalho uma sub-bacia hidrográfica (de ordem 2/microbacia) denominanda sub-bacia do Córrego de Nova Descoberta, afluente do Rio Morno (Figura 1). Esta sub-bacia possui uma extensão de 1,6 $\mathrm{km}^{2}$ e concentrou, somente em sua área, cerca de $96 \%$ dos eventos de escorregamentos registrados no bairro de Nova Descoberta, conforme o Banco de Dados da Defesa Civil Municipal de Recife, justificando a sua seleção.

A sub-bacia do Córrego de Nova Descoberta apresenta altitudes que variam entre 13 m e 90 m, que anterior à ocupação antrópica era composta por diversos córregos e riachos que, atualmente, encontram-se canalizados (canais urbanos de drenagem). Conforme Alheiros et al. (2003) e CPRM (2005), geologicamente, a área é formada por sedimentos miocênicos (Neógeno) da Formação Barreiras, cujos sedimentos são característicos de deposição fluvial. Apresentam camadas mais arenosas na base e arenosas e argilosas intercaladas nos topos, resultantes de depósitos por enxurradas (leques aluviais). A constituição de areias típicas dessa formação apresenta um elevado teor de feldspatos, sujeitos aos processos de argilização em função de climas quentes e úmidos, o que favorece a ocorrência de escorregamentos e de processos erosivos (ALHEIROS et al., 2003).

A região está inserida na unidade geomorfológica dos Tabuleiros Costeiros Dissecados (Planalto Sedimentar Litorâneo), no qual a dissecação desse relevo em direção à costa permitiu a formação de morros sinuosos e de colinas arredondadas com encostas de declividade elevada (ALHEIROS, 1998; CPRM, 2015; FONSÊCA et al.,2016). Conforme Fonsêca et al. (2016), a estrutura geral desse baixo planalto observa a disposição homoclinal do preenchimento da bacia Paraíba com flexura em direção à costa (FONSÊCA et al., 2016). A morfologia é dominada por divisores amplos e tabulares, dissecados por vales consequentes de primeira ordem, que normalmente confluem paralelamente para um coletor principal adaptado às estruturas lineares, interceptando transversalmente a linha de costa e acompanhando a direção preferencial das zonas de cisalhamento pré-cambrianas do embasamento (FONSÊCA et al., 2016). 
Conforme Lima (2002) e EMBRAPA (2000), os solos da região apresentam estratificações sub-horizontais, constituídas por sedimentos de textura variada, de areias a argilas, e por vezes, seixos rolados (quartzos). O processo pedogenético atuante sobre os sedimentos da Formação Barreira permitiu o desenvolvimento de solos profundos do tipo Argissolos, bastante suscetíveis a processos erosivos, e de Latossolos (LIMA, 2002). Destacase que esse contanto entre diferentes texturas de solo (argilosos e arenosos) favorece a ocorrência de escorregamentos translacionais devido ao favorecimento a zonas de rupturas nas áreas de contato, normalmente, mais instáveis.

O clima da área configura-se por ser quente e úmido, com precipitação média anual que ultrapassa os $2000 \mathrm{~mm}$. Os meses de Maio, Junho e Julho apresentam os índices de precipitação mais elevados, nos quais ocorrem os maiores números de ocorrências de escorregamentos (INSTITUTO NACIONAL DE METEOROLOGIA, 2016). Nesse sentido, os altos índices pluviométricos, muitas vezes um dos responsáveis pela instabilização das encostas da área, são condicionados pelos sistemas atmosféricos La Niña; pelas ZCITs (Zona de Convergência Intertropical), pelas VCANs (Vórtices Ciclônicos de Altos Níveis) e pelas DOLs (Distúrbios Ondulatórios de Leste) ou simplesmente Ondas de Leste, sob influência dos ventos alíseos, provocando precipitações intensas na região costeira do litoral do Nordeste, onde se localiza a área de estudo (OLIVEIRA et al., 2001).

Com relação à cobertura vegetal, apresentava, originalmente, vegetação de Mata Atlântica, substituída por diversos trechos de solo exposto e de vegetação secundária de pequeno porte (Figura 2), devido às altas taxas de desmatamento para a ocupação antrópica. Nesse contexto, as primeiras moradias da região estavam localizadas no nível de base do relevo ou nos topos dos morros (áreas mais aplainadas). Nas últimas décadas do século XX, esses locais passaram por um forte crescimento populacional em áreas de encostas (GALDINO, 2010). 


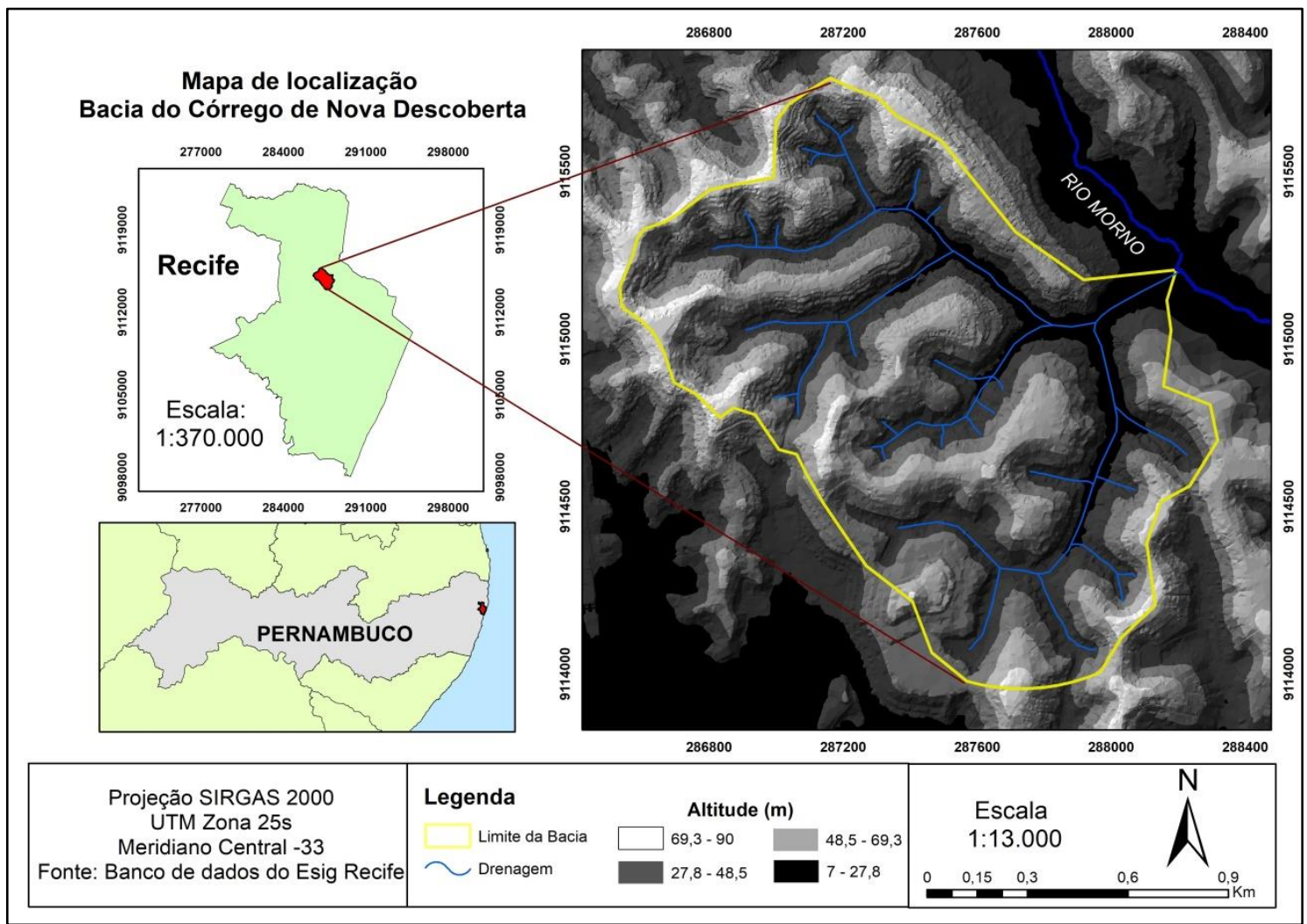

Figura 1: Mapa de localização da área de estudo (Sub-bacia do Córrego de Nova Descoberta).

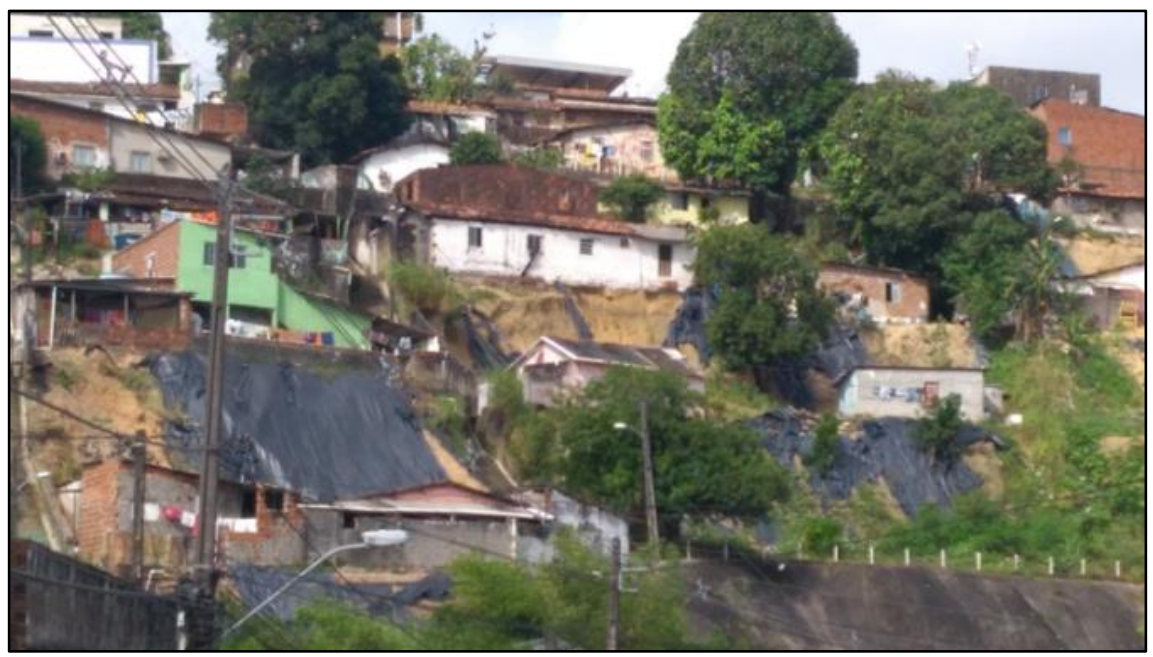

Figura 2: Encosta ocupada por moradias irregulares na área de estudo, onde é possível observar a presença de solo exposto e de vegetação secundária.

Existem diversas moradias localizadas em encostas declivosas (Figura 3), nas quais é comum a presença de habitações de grande porte sem o devido critério técnico ou de laudos profissionais para esse tipo de construção. Dessa forma, muitas residências possuem um sistema de drenagem construído sobre as encostas e canaletas, das quais em alguns casos o 
esgoto doméstico é lançado diretamente sobre o solo (lançamento de águas servidas diretamente nas encostas), aumentando a possibilidade de escorregamentos, mesmo em períodos de baixa pluviometria.

A região apresenta um histórico frequente de episódios de escorregamentos, como por exemplo, no ano de 1996, no qual 16 vítimas fatais foram contabilizadas e aproximadamente 1.000 moradores foram desabrigados. Este escorregamento foi deflagrado por um evento pluviométrico de $193 \mathrm{~mm}$ em 12h, responsável por mobilizar cerca de $50.000 \mathrm{~m}^{3}$ de solo (LIMA, 2002). Assim, entre 2013 e 2016, foram registradas pela Defesa Civil Municipal, a ocorrência de 87 escorregamentos, que atingiram diversas moradias. Tais ocupações passaram por um cadastramento de risco elaborado pela Defesa Civil, na qual foram classificadas em diferentes graus de risco em uma escala que varia de R1 (risco baixo) à R4 (risco muito alto), conforme a Tabela 1 .

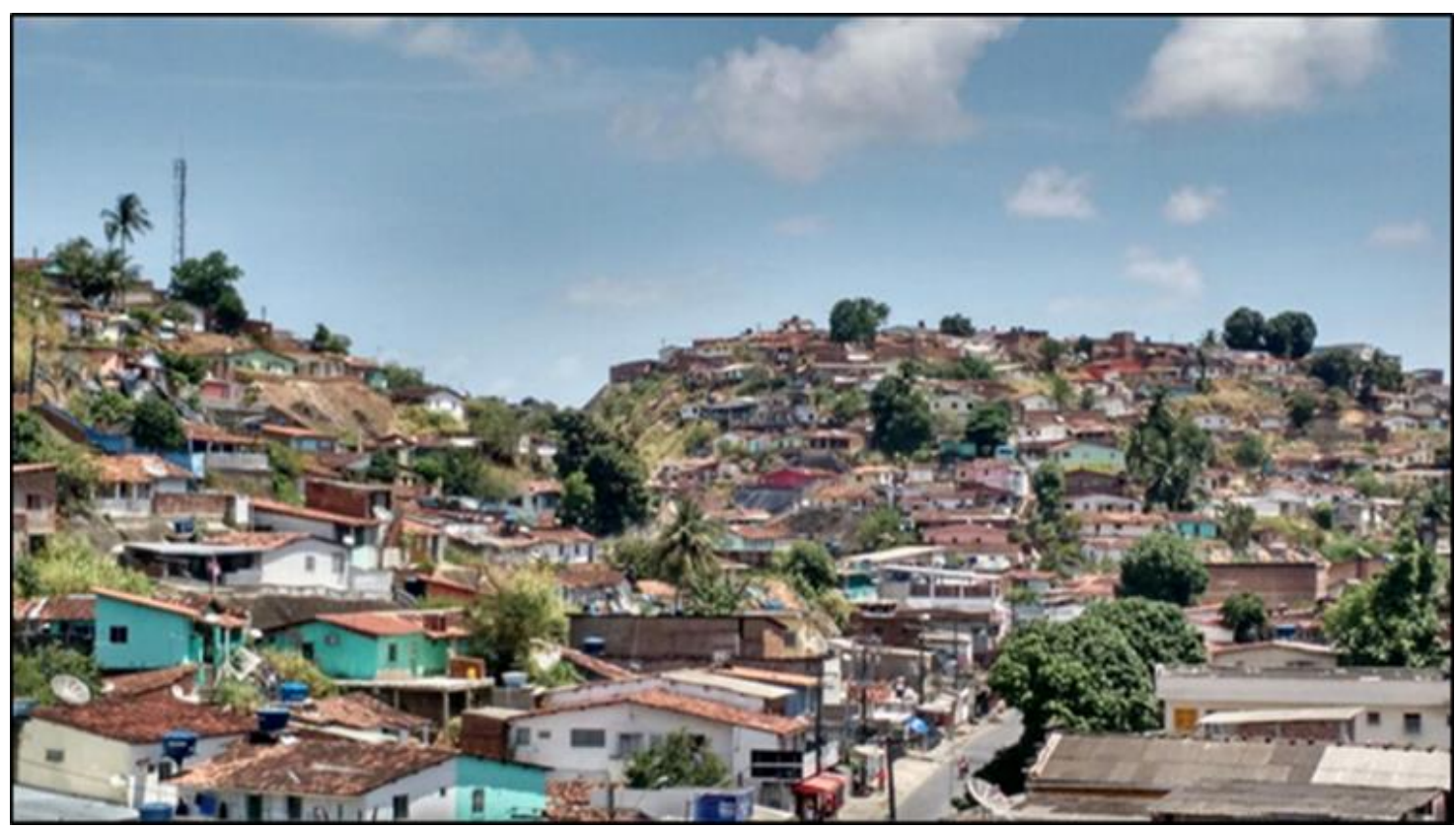

Figura 3: Encostam densamente ocupadas na sub-bacia do Córrego de Nova Descoberta, das quais foram registradas ocorrências de escorregamentos. 
Tabela 1: Grau de Risco das moradias que sofreram escorregamentos entre os anos de 2013 e 2016, cadastrados pela Defesa Civil municipal, na região da sub-bacia do Córrego de Nova Descoberta.

\begin{tabular}{c|c}
\hline Número de moradias em risco & Graus de Risco \\
\hline 17 & R4 (Risco muito alto) \\
\hline 68 & R3 (Risco alto) \\
\hline 7 & R2 (Risco médio) \\
\hline 2 & R1 (Risco baixo) \\
\hline
\end{tabular}

Fonte: Banco de Dados da Defesa Civil municipal do Recife.

A Prefeitura do Recife realiza, periodicamente, medidas mitigatórias na área para a prevenção de escorregamentos durante os períodos chuvosos. Além do monitoramento das áreas de risco, são colocadas algumas ações estruturais, como a construção de muros de arrimos e colocação de gel impermeabilizante. Da mesma forma, também são realizadas obras não estruturais, como a retirada de resíduos sólidos nas encostas, além da remoção de famílias onde as situações são mais perigosas.

Apesar da existência de ações estruturais e não estruturais, observa-se na região diversas encostas cobertas com lonas, muitas vezes por longos períodos e de forma definitiva e não paliativa. As contenções de encostas com lonas são medidas emergenciais e paliativas, não devendo ser colocadas como solução definitiva do problema. Destaca-se que tais lonas possuem duração curta (poucos dias), sendo facilmente desgastadas, entretanto sua presença é constante (Figura 4).

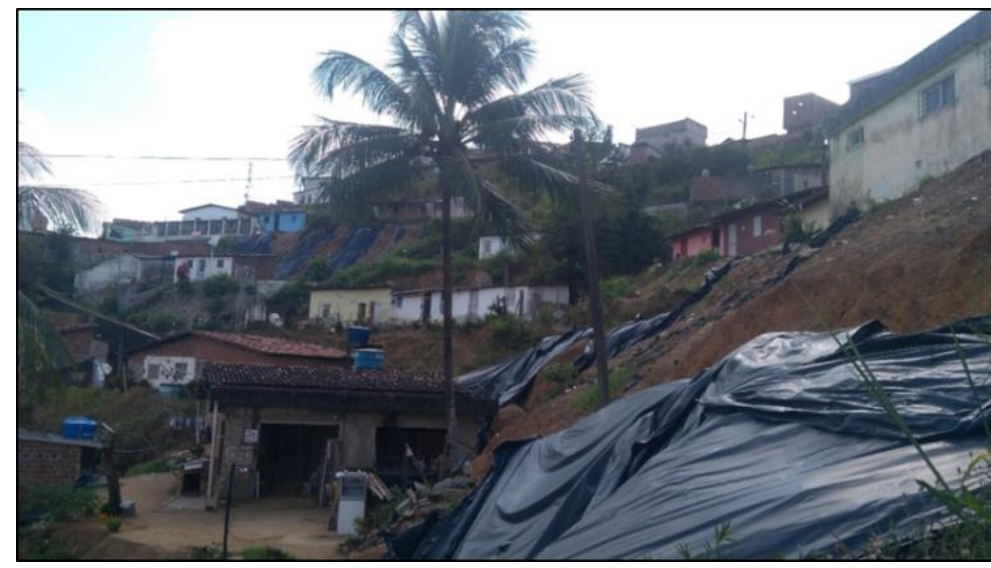

Figura 4: Encostas cobertas por lonas degradadas como medida emergencial à contenção das encostas. 


\section{MATERIAIS E MÉTODOS}

\section{Mapa de Ocorrências de Escorregamentos}

O mapa das ocorrências de escorregamentos foi elaborado a partir de um Banco de Dados Geográfico fornecido, gratuitamente, pela Defesa Civil do Município de Recife (Tabela 2), apresentando os locais de ocorrência dos processos na área de estudo entre os anos de 2013 e 2016. Os dados fornecidos pela Defesa Civil continham os endereços dos imóveis afetados, nome dos proprietários, data das ocorrências e, em alguns casos, as coordenadas UTM (Universal Transversa de Mercator).

Por meio do auxílio da fotointerpretração de imagens de satélite, adquiridas no banco de dados da CPRM (Companhia de Pesquisa de Recursos Minerais) e no Google Earth Pro, e também a partir de trabalhos de campo para validação, todos os dados obtidos pela Defesa Civil foram georreferenciados (atribuição de um par de coordenadas), sendo posteriormente plotados em um ambiente SIG. O mapa foi elaborado utilizando-se o software ArcGIS 10.3 (versão estudante), onde foram inseridas as coordenadas UTM dos locais afetados pelos escorregamentos, criando-se assim o mapa final de ocorrências de escorregamentos.

Tabela 2: Trecho do Banco de Dados disponibilizado pela Defesa Civil do município de Recife de onde foram capturadas as informações dos locais que sofreram escorregamentos entre 2013 e 2016 para a elaboração do mapa de ocorrências.

\begin{tabular}{|c|c|c|c|c|c|c|c|}
\hline Nordeste & 2013 & Junho & 31/05/2013 Deslizamentos de Barreiras & & RUA DOM FELICIANO, N. 955 & & \\
\hline Noroeste ${ }^{-}$ & $2013 \Gamma$ & Julho $F$ & 03/07/20 - Deslizamentos de Barreiras & $\Gamma$ & RUA FRANCISCO PASSOS, 26 & Colunas: & Colunas:- \\
\hline Nordeste & 2013 & Julho & 29/07/2013 Deslizamentos de Barreiras & & RUA ARABUTÃ, S/N & & \\
\hline Nordeste & 2013 & Julho & 29/07/2013 Deslizamentos de Barreiras & & RUA BAIANÓPOUS, № 66 & & \\
\hline Nordeste & 2013 & Julho & 31/07/2013 Deslizamentos de Barreiras & & RUA LONTRAS, № 50 & & \\
\hline Nordeste & 2013 & Julho & 31/07/2013 Deslizamentos de Barreiras & & RUA CAEM, № 96 & & \\
\hline Nordeste & 2013 & Julho & 31/07/2013 Deslizamentos de Barreiras & & RUA LONTRAS, № 49 & & \\
\hline Nordeste & 2013 & Agosto & 01/08/2013 Deslizamentos de Barreiras & & 3: TRAVESSA DAMOLÂNDIA, № 29 & & \\
\hline Nordeste & 2013 & Agosto & 01/08/2013 Deslizamentos de Barreiras & & 3! TRAVESSA DAMOLÁNDIA, ACIMA DA CASA Ne 28 & & \\
\hline Nordeste & 2013 & Agosto & 01/08/2013 Deslizamentos de Barreiras & & RUA CAPELINHA, № 29 & & \\
\hline Nordeste & 2013 & Agosto & 01/08/2013 Deslizamentos de Barreiras & & RUA CRAOLÂNDIA, NN 69 & & \\
\hline Nordeste & 2013 & Agosto & 01/08/2013 Deslizamentos de Barreiras & & RUA SANTA CATARINA, № 180 & & \\
\hline Nordeste & 2013 & Agosto & 12/08/2013 Deslizamentos de Barreiras & & ÚLTIMA TRAVESSA ALTO DA BRASILEIRA, № 08 & & \\
\hline Nordeste & 2013 & Agosto & 12/08/2013 Deslizamentos de Barreiras & & ÚLTIMA TRAVESSA ALTO DA BRASILEIRA, NN 08 A & & \\
\hline Nordeste & 2013 & Agosto & 12/08/2013 Deslizamentos de Barreiras & & 2: TRAVESSA ALTO DA BRASILEIRA, № 20 & & \\
\hline Nordeste & 2013 & Agosto & 12/08/2013 Deslizamentos de Barreiras & & ÚLTIMA TRAVESSA ALDO DA BRASILEIRA, № 44 & & \\
\hline Nordeste & 2013 & Agosto & 12/08/2013 Deslizamentos de Barreiras & & RUA ARABELA, № 83 & & \\
\hline Nordeste & 2013 & Agosto & 12/08/2013 Deslizamentos de Barreiras & & RUA ARABELA, № 83 B & & \\
\hline Nordeste & 2013 & Agosto & 13/08/2013 Deslizamentos de Barreiras & & RUA DO CACACU, № 35 & & \\
\hline Nordeste & 2013 & Agosto & 11/07/2013 Deslizamentos de Barreiras & & RUA DO CACAU, № 35 & & \\
\hline Nordeste & 2013 & Agosto & 16/08/2013 Deslizamentos de Barreiras & & RUA DOM FEUCIANO, NN 55 & & \\
\hline Nordeste & 2013 & Agosto & 16/08/2013 Deslizamentos de Barreiras & & RUA DO CACAU, № 11 & & \\
\hline Nordeste & 2013 & Agosto & 20/08/2013 Deslizamentos de Barreiras & & RUA SÃO LUIS, N. 230 & & \\
\hline Nordeste & 2014 & Junho & 30/06/2014 Deslizamentos de Barreiras & & Rua Nazareno, 21 & 25L. 286992 & UTM 9114869 \\
\hline Nordeste & 2014 & Junho & 30/06/2014 Deslizamentos de Barreiras & & Rua Nazareno, 61 & 25L. 287039 & UTM 9114856 \\
\hline Nordeste & 2014 & Julho & 09/07/2014 Deslizamentos de Barreiras & & Rua Cgo. Inácio, 306 & $25 \mathrm{M} 287157$ & UTM 9115665 \\
\hline Nordeste & 2014 & Julho & 15/07/2014 Deslizamentos de Barreiras & & Rua do Nazareno, 05 & & \\
\hline Nordeste & 2014 & Setembro & 08/09/2014 Deslizamentos de Barreiras & & Rua Poti, $n^{*} 23$ & & \\
\hline Nordeste & 2015 & Março & 06/03/2015 Deslizamentos de Barreiras & & Rua Irecê, 08 & 287148 & 9114810 \\
\hline Nordeste & 2015 & Março & 06/03/2015 Deslizamentos de Barreiras & & Rua Irecê, 12-A & & \\
\hline Nordeste & 2015 & Março & 09/03/2015 Deslizamentos de Barreiras & & Rua Putinga, 80 & 287276 & 9115559 \\
\hline Nordeste & 2015 & Março & 10/03/2015 Deslizamentos de Barreiras & & 2.e Trav. Alto do Reservatório, 88 & 287005 & 9115628 \\
\hline Nordeste & 2015 & Março & 12/03/2015 Deslizamentos de Barreiras & & Rua Alto do Reservatório, $\mathrm{S} / \mathrm{N}$ & 286604 & 9115323 \\
\hline Nordeste & 2015 & Abril & 27/04/2015 Deslizamentos de Barreiras & & Rua Arantina, $N^{\circ} 40$ & 287874 & 9115228 \\
\hline Nordeste & 2015 & Maio & 06/05/2015 Deslizamentos de Barreiras & & Rua Arabela, 04-A & 287082 & 9115080 \\
\hline
\end{tabular}

Fonte: Acervo da Defesa Civil municipal de Recife. 
Análise das alterações morfológicas das encostas

Visando compreender as alterações morfológicas das encostas presentes na área de estudo ao longo de um período evolutivo, foram criados perfis topográficos das áreas que mais sofreram processos de escorregamentos (Figura 5); identificados na etapa anterior conforme o mapa de ocorrências. Dessa forma, foram criados 12 perfis comparativos (das mesmas áreas), mas de anos distintos (6 perfis de 1975 e 6 perfis de 2013) visando verificar as principais alterações morfológicas sobre o relevo causadas pela ocupação da área ao longo destes 38 anos.

Seguindo o referencial teórico e a nomenclatura proposta por RODRIGUES (2005), admite-se que a morfologia do ano de 1975 é mais próxima a uma morfologia original em um estágio de pré-perturbação (baseada nas baixas taxas de ocupação daquele ano cujos parâmetros declividade, rupturas e mudanças de declives não sofreram alterações significativas por intervenções antrópicas). Já a de 2013, se caracteriza como uma morfologia antropogênica, devido o excesso de cortes, de aterros, de construções, de alterações nos padrões naturais de drenagem, dentre outras intervenções sobre o relevo original e, consequentemente, alterações topográficas na paisagem (pós-perturbação antrópica).

É importante destacar que foram utilizados dados de 1975 (como morfologia original) em função da melhor qualidade da escala, dentro do conjunto de dados disponíveis para a década de 1970 (e de que não há dados de décadas inferiores para esta análise). Assim, os perfis topográficos de 1975 (morfologia original) foram criados tendo como dados de entrada a ortofotocarta da região disponibilizada pela CONDEPE FIDEN - Agência Estadual de Planejamento e Pesquisas de Pernambuco (Folha 81-Recife-A285000mE) em escala 1:10.000 elaborada em 1975 (ano da cobertura aérea sobre a topografia local/sobrevôo) com equidistância de $5 \mathrm{~m}$ (Figura 6). A carta foi georreferenciada e vetorizada em ambiente SIG (software ArcGIS) utilizando o grupo de ferramentas ArcScan.

Os perfis topográficos de 2013 (morfologia antropogênica) tiveram como base as curvas de nível geradas por um aerolevantamento realizado pela Prefeitura do Recife em 2013 (Projeto ESIG Recife), que visou atualizar as informações da base cartográfica da cidade (iniciativa municipal), com equidistância de $1 \mathrm{~m}$, escala 1:5.000 e que foram obtidas também gratuitamente (Figura 6).

Ambos os perfis topográficos foram criados por meio do software ArcGIS, aplicando o grupo de ferramentas 3D Analyst (Interpolate line), de onde foram elaborados MDTs (Modelos Digitais do Terreno), do tipo TIN, de ambos os anos de onde foram extraídos os 
perfis. Dessa forma, foram avaliadas as alterações topográficas na paisagem, muitas delas causadas por interferências antropogênicas durante o período (1975-2013), propiciando, dessa forma, analisar o papel da ocupação urbana (práticas inadequadas) na deflagração dos escorregamentos da região (diferenças entre a morfologia original e a morfologia antropogênica ou ainda, diferenças entre o estágio de pré-perturbação antrópica e pósperturbação/perturbação ativa). Para finalizar esta etapa, foram realizados trabalhos de campo na área, com o objetivo de avaliar as principais intervenções (pressões antropogênicas) atuais na paisagem e validar os dados.

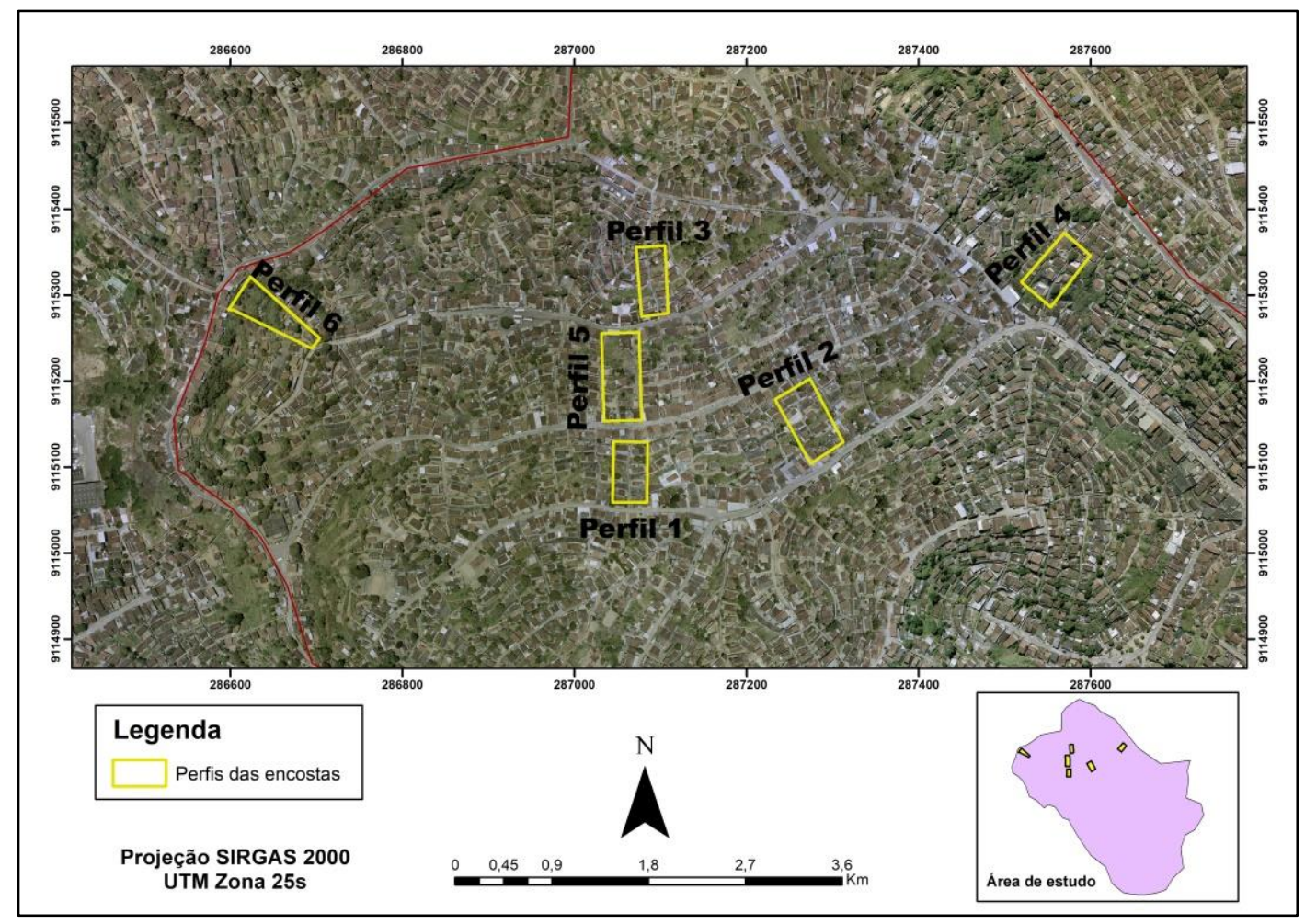

Figura 5: Localização dos 6 perfis topográficos das encostas avaliadas neste trabalho para cada ano (1975 e 2013). Abaixo a localização destas encostas em relação à área de estudo. 


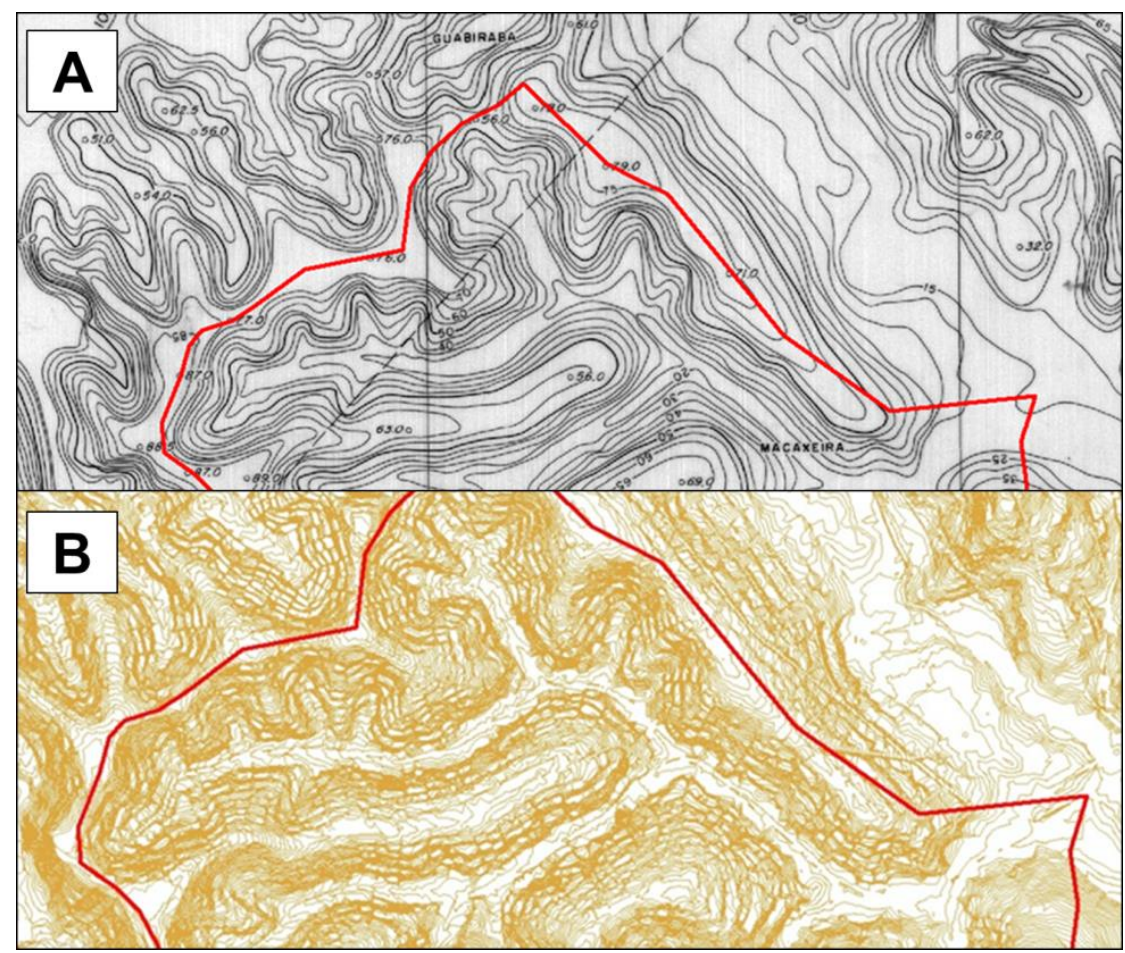

Figura 6: (A) Carta Topográfica do ano de 1975 (CONDEPE-FIDEN) georreferenciada e inserida em ambiente SIG para a análise da morfologia original e (B) Base planialtimétrica extraída das curvas de nível do ano de 2013 (ESIG-Recife) utilizada para avaliar a morfologia antropogênica.

\section{RESULTADOS E DISCUSSÕES}

\section{Mapeamento das ocorrências de escorregamentos}

De acordo com o Banco de Dados da Defesa Civil do Recife, entre 2013 e 2016, foram registradas 90 ocorrências de escorregamentos no bairro de Nova Descoberta. Deste total, 87 (96\%) aconteceram dentro dos limites da sub-bacia do Córrego de Nova Descoberta (Figura 7). A maior parte dos escorregamentos se concentrou na região norte da área e foram registrados, com maior frequência, entre os meses de março e de agosto (período chuvoso) destes respectivos anos.

Muitos destes escorregamentos ocorreram em locais em que há o lançamento de água servida diretamente nas encostas. Além disso, diversos vazamentos de tubulações foram verificados em campo, causando a saturação dos solos, mesmo em períodos de baixa pluviometria, conforme a Figura 8. Estes não receberam a devida manutenção e aumentaram consideravelmente a quantidade de água nas camadas sub-superficiais do solo. Assim, há registros de escorregamentos causados pelo rompimento de canos de distribuição em 2013, em que quatro moradias foram atingidas (G1-PE, 2013). 
Outra prática comum na região é a alta taxa de desmatamento. Praticamente, toda a vegetação original foi retirada, restando trechos remanescentes de vegetação original, sendo comum, portanto, a presença de solo exposto e de vegetação herbácea. Associado a esta situação, é visível também a presença de depósitos tecnogênicos, que acabam aumentando consideravelmente o peso sobre as encostas e também estão sujeitos a deslizamentos.

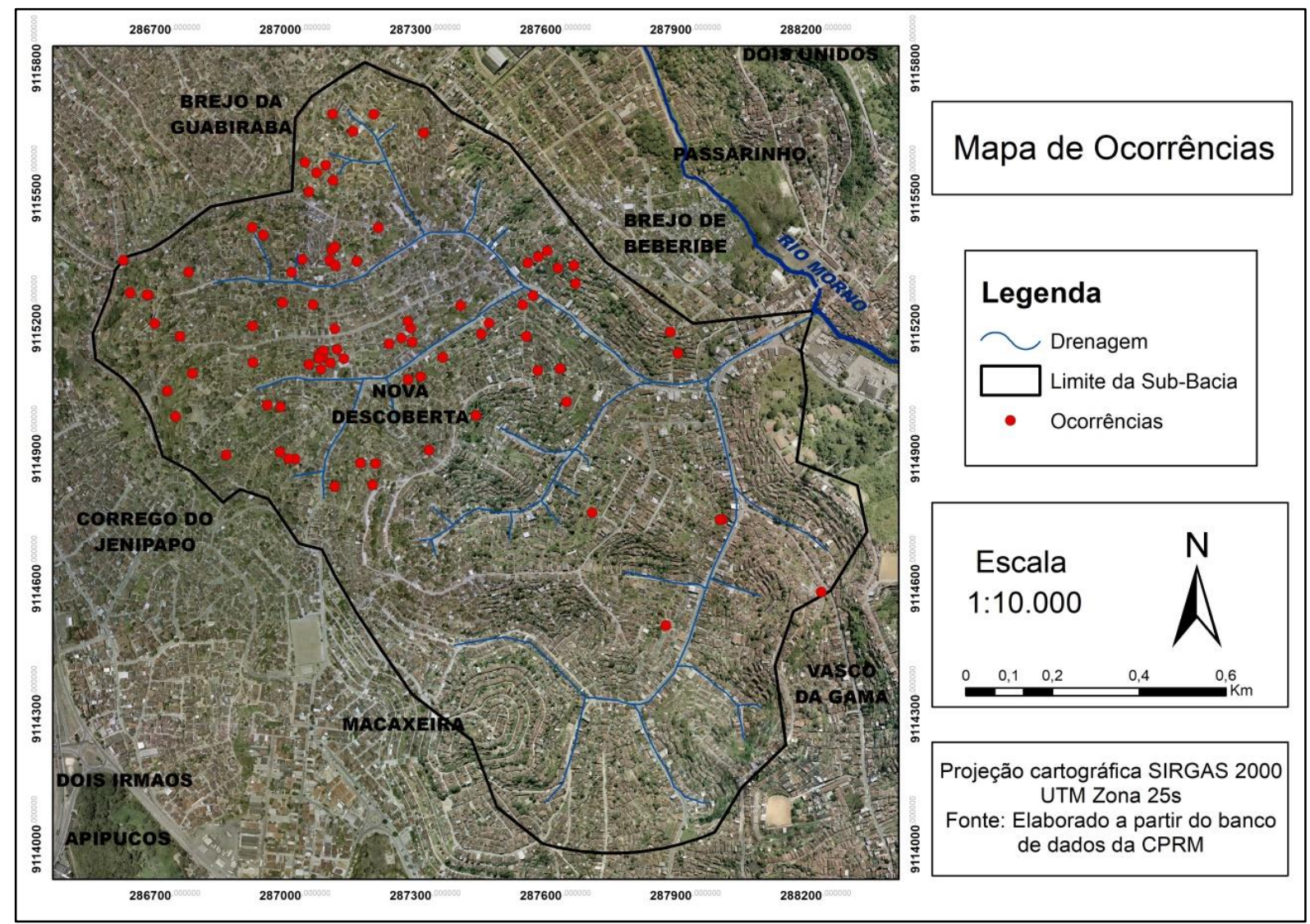

Figura 7: Mapa de Ocorrências de Escorregamentos. Observa-se uma distribuição superior a norte da área de estudo. 


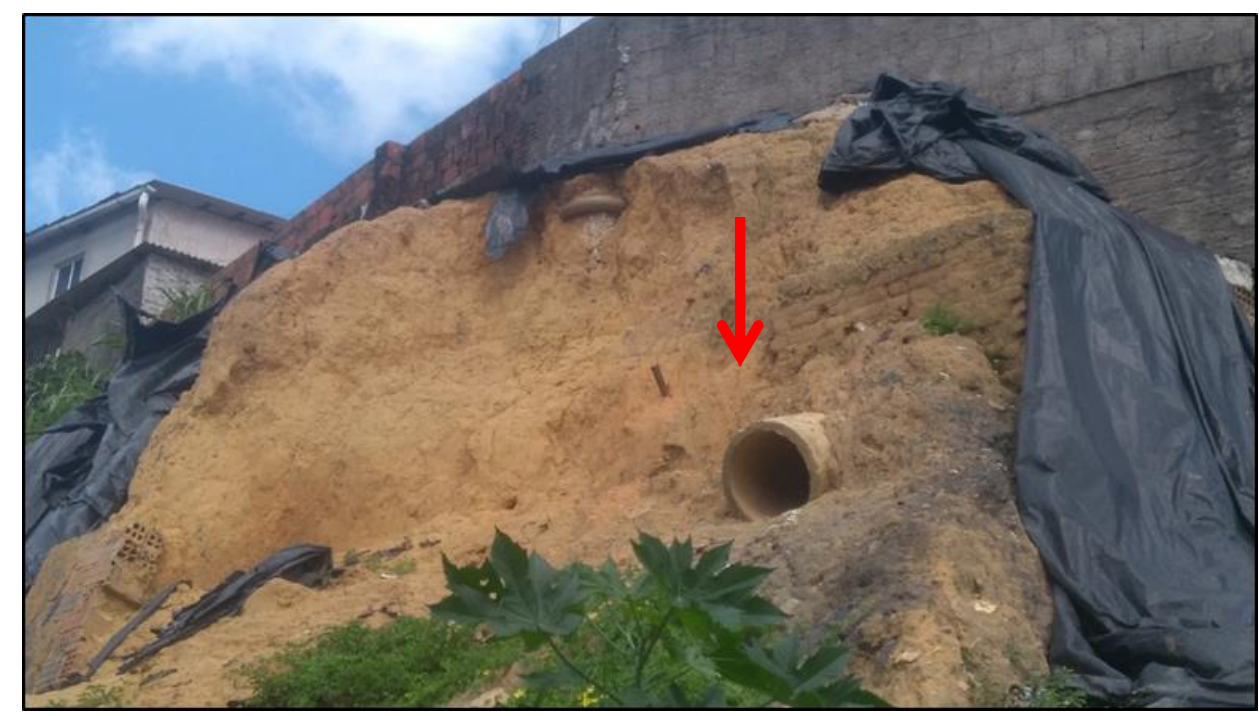

Figura 8: Lançamento de água diretamente na encosta (seta vermelha) que, muito provavelmente, deflagrou um evento de escorregamento.

\section{Morfologia original e morfologia antropogênica}

Com base nos perfis topográficos criados para cada período (1975 e 2013) conforme a Figura 9, ficou bastante evidenciado que as encostas sofreram alterações significativas em sua morfologia original dentro deste período de 38 anos, devido o aumento de áreas antrópicas, desprovidas de um adequado planejamento urbano. Nesse sentido, a sub-bacia avaliada, se encontra predominantemente antropizada, na qual a morfologia original da região fora quase totalmente alterada.

Todas as encostas das quais foram elaborados os perfis, tiveram alterações em sua morfologia, especialmente, em sua forma, declividade, criação de patamares/declives e rupturas devido as interferências antrópicas supracitadas (Figura 9). Tais alterações foram provenientes da realização de cortes e de aterros, muitas vezes mal executados e realizados pela população local (autoconstrução), muito comum em áreas de risco e que acabam tendo um papel relevante na deflagração de escorregamentos devido o aumento da instabilidade e da ausência de obras geotécnicas de proteção significativas.

Os cortes alteraram a pedogênese das encostas e retiraram a sua proteção natural (horizontes do solo e vegetação) deixando-as mais suscetíveis a escorregamentos em períodos de pluviometria mais intensa. Da mesma maneira, os aterros se apresentam, de forma geral, pouco compactados e incoesos, altamente suscetíveis a deslizamentos. 
Deve-se também considerar o excesso de compactações de depósitos tecnogênicos (ex. sedimentos residuais da construção civil) e de material coluvionar (sedimentos de encostas) também com decréscimo de coesão e redução de estabilidade. Assim, em linhas gerais, podese afirmar que a ocupação criou knickpoints artificiais que romperam o perfil de equilíbrio das encostas e geraram taludes artificiais com declividades incompatíveis com o ângulo de repouso dos materiais que estruturam esse relevo (sedimentos incoesos da Formação Barreiras).

Embora admite-se que os perfis topográficos possam apresentar um certo grau de erro de precisão, devido as rotinas automatizadas na representação das morfologias das encostas, ainda é possível afirmar, ou seja, é válido, o fato de que as encostas foram severamente alteradas no período avaliado. Dessa forma, as morfologias antropogênicas estão muito distantes de sua morfologia original, que ao serem somadas a herança geológicageomorfológica da paisagem local (Formação Barreiras e Tabuleiros Costeiros Dissecados) e aos altos índices pluviométricos (isoietas próximas a $2000 \mathrm{~mm}$ ) aumentam, consideravelmente, o risco de ocorrências de escorregamentos na área. 


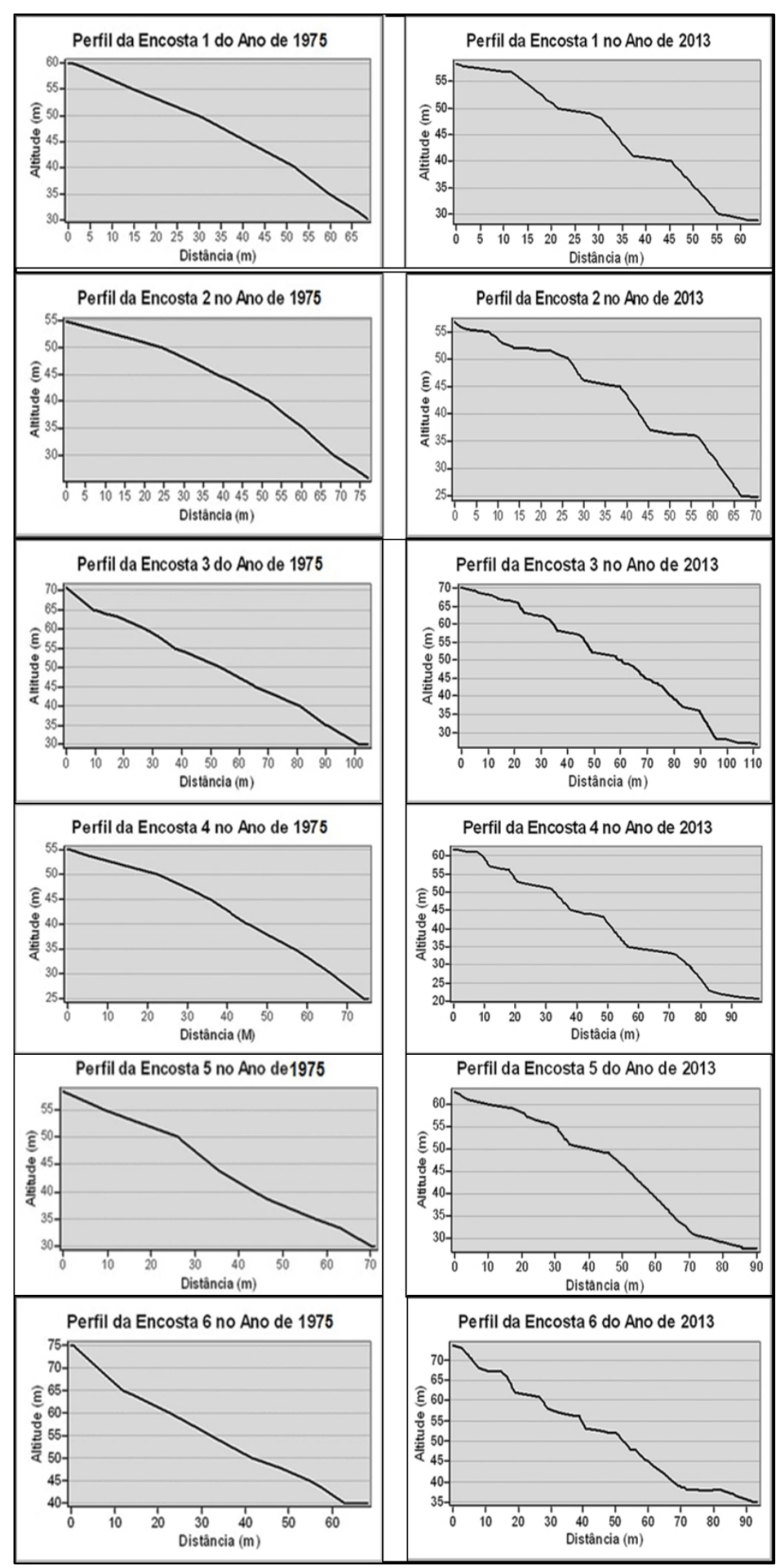

Figura 9: Comparação dos Perfis Topográficos das encostas (1975 e 2013) para avaliação das morfologias originais e morfologias antropogênicas. 


\section{CONSIDERAÇÕES FINAIS}

De acordo com os resultados deste trabalho, as alterações na morfologia das encostas já naturalmente instáveis (devido suas características geológicas e geomorfológicas) acarretaram em uma concentração significativa de escorregamentos. Demais ações, como as altas taxas de desmatamentos e a exposição dos solos, que embora num primeiro momento favoreçam o escoamento superficial e a formação de processos erosivos, potencializam, posteriomente, a ocorrência de escorregamentos. A drenagem urbana e as tubulações de distribuição de água apresentaram um peso significativo na ocorrência dos processos, na medida em que há presença de água nas encostas, mesmo em períodos de baixa pluviometria.

A elaboração do mapeamento de áreas de ocorrência dos escorregamentos é, também, uma importante medida em estudos relacionados a instabilidade de encostas, uma vez que cada ponto do mapa representa uma área de instabilidade. Dessa forma, pode se admitir que nas áreas onde já ocorreram escorregamentos no passado, poderão ocorrer no futuro, devido seu grau de instabilidade na paisagem.

Com relação às medidas mitigadoras vistas em campo para a proteção de encostas, existe a necessidade da aplicação de obras estruturais e não estruturais mais duradouras, tais como muros de arrimo, retaludamentos, entre outras, além de obras de reurbanização e remoção de moradias, uma vez que as ocorrências de escorregamentos mostraram-se frequentes na área.

O mapeamento realizado nessa pesquisa, bem como as análises indicadas pelas alterações das morfologias das encostas, puderam indicar os parâmetros relevantes na deflagração dos escorregamentos atuais. Deve-se destacar que o uso das Geotecnologias em estudos geomorfológicos torna os trabalhos extremamente objetivos, economizando tempo e recursos ficanceiros; embora também necessitem de análise crítica e acurácia. Portanto, os resultados destas análises podem auxiliar a compreensão da dinâmica de processos superficiais que, embora naturais, muitas vezes acabam sendo potencializados pela ação antrópica, assumindo a dimensão de desastres, que geram perdas consideráveis tanto econômicas quanto sociais. 


\section{AGRADECIMENTOS}

Os autores agradecem à Defesa Civil do município de Recife, pelo fornecimento do Banco de Dados de ocorrência de escorregamentos, e aos professores Dr. Antônio Carlos de Barros Corrêa (UFPE) e Dr. Osvaldo Girão da Silva (UFPE) pelos importantes comentários, discussões e sugestões.

\section{REFERÊNCIAS}

ALHEIROS, M. M.; SOUZA, M. Â. A.; BITOUN, J; MEDEIROS, S. M. G. M.; JÚNIOR, W. M. A. Manual de Ocupação dos Morros da Região Metropolitana do Recife. Fundação de Desenvolvimento Municipal FIDEM; coord. Margareth Mascarenhas Alheiros... (et al.). - Recife: Ensol, 2004.

ALHEIROS, M.M. Risco de escorregamentos na Região Metropolitana do Recife. Tese(Doutorado) - Geologia Sedimentar, UFBA, Salvador - BA, p. 129, 1998.

ARAI, M. A Grande Elevação Eustática do Mioceno e Sua Influência na Origem do Grupo Barreiras. Geol. USP, Sér. cient, v.6, n. 2, p. 1-6, 2006.

CARVAlHO, C. S.; OGURA; A. T.; MACEDO, E. S. Mapeamento de Risco em Encostas e Margens de Rios. Ministério das Cidades / Instituto de Pesquisas Tecnológicas - IPT, p. 9$32,2007$.

DREW, D. Processos interativos homem-meio ambiente. ed. 3, Rio de Janeiro: Bertrand Brasil, 1994.

FERNANDES, N. F.; AMARAL, C. P. (1996). Movimentos de massa: uma abordagem Geológico-Geomorfológica. In: GUERRA, A.T.; CUNHA, S.B. da. Rio de Janeiro: Geomorfologia e Meio Ambiente. P. 123-194.

FERNANDES, N. F.; GUIMARÃES, R. F.; GOMES, R. A. T.; VIEIRA, B. C.; MONTGOMERY, D. R.; GREENBERG, H. Condicionantes geomorfológicos dos deslizamentos nas encostas: avaliação de metodologias e aplicação de modelo de previsão de áreas susceptíveis. Rev. Bras. Geomorfol, Vol. 2, Nº 1, 2002.

FONSÊCA, D. N.; CORRÊIA, A. C.; SILVA, A. C. Compartimentação Geomorfológica da Região Metropolitana do Recife (RMR) a Partir da Análise Morfoestrutural. Rev. Geo UFRJ, p. 201-219, 2016.

FUNDAJ (FUNDAÇÃO JOAQUIM NABUCO). Mapa de Exclusão/Inclusão Socioambiental do Recife. FUNDAJ: Recife, 2007. 
GALDINO, D. Nova Descoberta: Recortes dos Territórios e Territorialidades em um Bairro da Cidade do Recife. Web Artigos, 2010.

GUERRA, A. J. T.; MARÇAL, M. S. Geomorfologia Ambiental. Rio de Janeiro, Bertrand Brasil, 2006.

INSTITUTO NACIONAL DE METERIOLOGIA (IMMET). Climatologia dos Meses e Trimestres de Maiores ou Menores Temperaturas e Pluviosidades médias no período de 1961-2009. Disponível em: www.inmet.gov.br/portal/index.php?r=clima/mesTempo. Último Acesso em 11/03/2018.

LIMA, F. L. Comportamento Geomecânico e Análise de Estabilidade de uma Encosta da Formação Barreiras na Área Urbana da Cidade do Recife. Dissertação de Mestrado, Programa de Pós-Graduação em Engenharia Civil, UFPE, 2002.

MONTGOMERY, D.R.; DIETRICH, W.E. A physically-based model for the topographic control on shallow landsliding. Water Resources Research (30). p. 1153-1171, 1994.

OLIVEIRA, G.C.S.; JUNIOR, J.P.S. NÓBREGA, R.S; GIRÃO, O. Uma Abordagem da Geografia do Clima Sobre os Eventos Extremos de Precipitação em Recife-PE. Rev. Bras. Geo. Fís, v.02, p.238-251,2011.

PFALTZGRAFF, A. S. Mapa de Suscetibilidade a Deslizamentos na Região Metropolitana Do Recife. Tese (Doutorado), Programa de Pós-Graduação Em Geologia, UFPE, 2007.

PREFEITURA DO RECIFE. Serviços Para o Cidadão. Disponível em: http://www2.recife.pe.gov.br/servicos/cidadao. Último acesso em 11/02/17.

RODRIGUES, C. Morfologia Original e Morfologia Antropogênica na Definição de Unidades Espaciais de Planejamento Urbano: Exemplo na Metrópole Paulista. Revista do Departamento de Geografia (USP), v.17, p.101-111, 2005.

RODRIGUES, F. S.; LISTO, F.L.R. Mapeamento de áreas de risco a escorregamentos e inundações em áreas marginais a rodovias na Região Metropolitana de São Paulo. Engenharia Sanitária e Ambiental (Online), v. 21, p. 1-11, 2016.

SELBY, M. J. Hillslope: Materials \& Processes. New York. Publisher: Oxford University Press. USA. p. 480, 1993.

TOMINAGA, L. K.; SORTORO, J; AMARAL, R.(org.). Desastres Naturais: Conhecer Para Prevenir. Instituto Geológico, São Paulo, ed. 1, 2009.

TRICART, J. Ecodinâmica. Rio de Janeiro: IBGE; SUPREN, p. 191, 1977. 